\title{
Relationship of Downy Mildew Resistance with Marker and Yield Related Traits Helpful for Achieving Reliable Selection Criteria in Opium Poppy (Papaver somniferum L.)
}

\author{
M.K. Dubey ${ }^{1,2}$, S.K. Singh ${ }^{1}$ and O.P. Dhawan ${ }^{1}$ \\ ${ }^{1}$ Genetics \& Plant Breeding Division, CSIR-Central Institute of Medicinal and Aromatic \\ Plants (CSIR-CIMAP), Lucknow, 226015, India \\ ${ }^{2}$ Present address: Uppsala BioCenter, Department of Forest Mycology and Plant \\ Pathology, Swedish University of Agricultural Sciences, Box 7026, 75007, Uppsala, \\ Sweden
}

Keywords: correlations, downy mildew, Papaver somniferum, path analysis, Peronospora arborescens, straw alkaloids

\begin{abstract}
Opium poppy (Papaver somniferum L.), one of the oldest medicinal plants, produces more than eighty alkaloids including the analgesic morphine, the antitussive codeine and the muscle relaxant papaverine. Beside alkaloids, the crop is cultivated for seeds and seed oil. Downy mildew (DM) caused by fungus Peronospora arborescens (Berk) de Bary is one of the most destructive diseases of opium poppy which causes enormous loss in terms of both opium and seed yield. Therefore, development of DM-resistant poppy cultivars with high seed and straw yield is the most sustainable objective in opium poppy breeding. In the present study, the nature and degree of relationships between different marker and yield influencing traits including DM-resistance were studied using correlation and path coefficient analysis. The observations strongly support the effectiveness of selections for high seed and straw yield together with DM resistance by considering the said component traits individually or in combination for developing effective selection criteria for crop improvement. The results would help in development of disease resistant and high yielding cultivars in opium poppy.
\end{abstract}

\section{INTRODUCTION}

The pharmaceutical significance of opium poppy (Papaver somniferum L.) in modern medicine is mainly because of the three morphinane alkaloids; morphine, codeine, thebaine and the three phthalideisoquoline alkaloids; papaverine, narcotine and narcine. Morphine is a strong analgesic, while codeine is antitussive and antispasmodic (Facchini et al., 2003). The poppy-straw (capsule hull and peduncle) is the site of alkaloid accumulation, which can also be solvent-extracted and concentrated chemically for diverse pharmaceutical uses (Sharma et al., 1994). In addition, the opium poppy is cultivated as a source of poppy seeds (Husain and Sharma, 1983) and seed oil, which is rich in unsaturated fatty acids (Tetenyl, 1996).

The opium poppy plant is vulnerable to several fungal, bacterial and viral pathogens. Downy mildew (DM) is the most alarming and widespread fungal disease caused by an ascomycetous fungus Peronospora arborescens. The infected plants develop two kinds of symptoms, namely systemic and topical (Kothari and Prasad, 1970). The plants with systemic infection die prematurely and cause severe losses in terms of both opium and seed yield, while those with topical infections survive with reduced growth and development as compared to healthy plants (Dubey, 2008). Development of DM resistant cultivars with high seed and straw yielding traits is required for opium poppy breeding. Studies involving 35 opium poppy accessions have been conducted here to obtain genetic associations using correlation and path analysis. In this study, the nature and degree of relationships between different markers and yield influencing traits including the DM-resistance are analyzed with an aim to facilitate selection strategies for development of disease resistant and high yielding cultivars in opium poppy. 


\section{MATERIALS AND METHODS}

\section{Plant Material and Cultural Practices}

Thirty five different accessions of opium poppy, maintained at National Gene Bank of Medicinal and Aromatic Plants at CSIR-Central Institute of Medicinal and Aromatic Plants (CSIR-CIMAP), Lucknow, India, were used in this study. The sources of origin of these accessions are presented in Table 1.

The field experiments were conducted with the above 35 different accessions in randomized block design (RBD) with three replications (plot size $4 \mathrm{mx} 4 \mathrm{~m}$ per replication with rows $40 \mathrm{~cm}$ apart). The experiments were carried out during three consecutive years (2004-05 to 2006-07) at the experimental field station of CSIR-CIMAP and also under glass house conditions. For the field experiments, standard cultural practices for the region were implemented throughout the growing season. In glasshouse, the seeds were sown in earthen pots $(25 \mathrm{~cm}$ diameter) in four replications (three replications for inoculation and one replication served as control). Inoculum of Peronospora arborescens was prepared from young plants of opium poppy as described in Dubey et al. (2009). Ten competitive plants of each replication were selected for observations of various morphometric traits.

\section{Screening of Opium Poppy Accessions for Resistance against $P$. arborescens}

Disease reactions were scored on ten plants in each row of each plot in the field trial and ten plants in each replication in the glasshouse trial until the flowering stage on the basis of necrotic spots on the leaves and spread of conidiophores on the lower surface of leaves on $0-9$ scale. Disease severity was scored as follows: $0-1.0=0-10 \%$ infection, $1.1-2.0=11-20 \%, 2.1-3.0=21-30 \%$, through $8.1-9.0=80-90 \%$ infection on leaves (disease intensity) of each plant. Disease severity index (DSI) was calculated for each of the 35 selected germplasm accessions by the formula described in Dubey et al. (2009).

Correlation coefficients among different marker and yield contributing traits such as plant height, leaf area (third leaf from top; $\mathrm{cm}^{2}$ ), number of capsules per plant, number of stigmatic rays per capsule (central capsule), capsule diameter (central; cm), capsule length (central; cm), straw yield per plant (g), seed yield per plant (g) and DSI for DM resistance in field and glasshouse for each accession were calculated according to the method of Miller et al. (1958), whereas co-heritability of a pair of characters was calculated by using the method of Hazel (1943). Path coefficient was calculated according to Dewey and $\mathrm{Lu}$ (1959) selecting straw yield as dependent variable and the nine plant characteristics (mentioned above) as independent variables.

\section{RESULT AND DISCUSSION}

Mean values of the data recorded for 10 different marker and yield contributing traits for each accession are given in Table 2. On the basis of the DSI values, obtained from the trial in glasshouse and field conditions, 35 genotypes of opium poppy are classified into highly resistant $(0.00-12.21)$, resistant (12.22-33.33), tolerant (33.3455.55), susceptible (55.56-77.77), and highly susceptible (77.78-99.99) (Table 3 ).

\section{Character Association between DSI for Downy Mildew and Other Morphometric Traits}

In order to develop selection criteria for developing DM-resistant and high yielding cultivar, the relationships among DM-resistance and yield contributing traits need to be demonstrated. Correlation coefficients measure the mutual associations between any two traits and also have a direct attitude on selection of different characters for breeding programs. Coefficients of genotypic correlations (rg) and phenotypic correlations (rp) were computed to estimate the degree of linear associations among various selected morphometric traits (Table 4; above diagonal). Most of the correlations were found to be significant. With regard to correlations expressed in terms of character associations, both positive and negative associations were observed among all the traits at 
genotypic and phenotypic level. The phenotypic and genotypic correlations were of same sign, though genotypic correlation values were somewhat higher than the phenotypic values in most cases. This suggested that there was strong inherent correlation among the selected traits and influence of the environment on these correlations was minimal (Falconer, 1989).

The DSI for DM-resistance showed negative correlation with all the traits considered in this study. However, the values were significant only with seed and straw yield per central capsule (Table 4; above diagonal). This illustrates that while making selections for high seed and straw yield, emphasis should be given not only to these various morphometric traits but also on the DM resistance or susceptibility. Similar results for significant and negative association of DSI with respect to collar rot and damping-off with traits like seed and straw yield have been reported earlier (Trivedi et al., 2006). Non-significant association among DSI and other marker and yield contributing traits in our study suggested that these traits at genetic level might be governed separately of disease resistance or susceptibility and therefore could be improved collectively but separately.

In our study, besides DSI for DM resistance all other selected traits showed significant positive correlations with each other. Seed and straw yields are the most important economic traits of opium poppy. The significant positive correlation between them and with remaining traits indicated that these are genetically dependent on each other and therefore could be improved by selecting unanimously or individually (Singh et al., 2003; Jain et al., 2005). Our results from correlation analysis, in which seed yield was found positively correlated with number of stigmatic rays on the central capsule is in line of earlier reports by Trivedi et al. (2006).

In order to investigate the co-inheritance pattern, co-heritability of different pairs of characters was studied. Higher co-heritability values were found between all the characters studied (Table 4; below diagonal) which suggested that increase in one of the characters would couple with an increase in its co-heritable characters (Lal et al., 1996).

\section{Path Coefficient Analysis}

The genetic correlations were further explored using path coefficient analysis. This technique splits the correlation coefficients into direct and indirect effects via alternative characters, measures the relative importance of direct and indirect effects and thus permits a critical examination of components that influence a given correlation and can be helpful in formulating an efficient selection strategy (Scheiner, 2000; Shipley et al., 1997). Besides, it also allows a better understanding of the interrelationships with all possible combinations between all the selected traits. Path analysis has been used to define the best criteria for selection in biological and agronomic studies (Mishra and Drolsom, 1973; Williams et al., 1990). In the present study path analysis was performed considering straw yield as a dependent character while rest of the traits was selected as independent characters (Table 5).

Path analysis showed that the capsule diameter contributed directly and positively to the straw yield to the highest extent. The next highest positive and direct contribution to straw yield was made by number of stigmatic rays followed by number of capsules/plant. Both of these traits also contributed indirectly through capsule diameter. Despite that, all other traits except DSI as recorded in experiments conducted in glass house and field conditions in this study were found to contribute indirectly to straw yield through capsule diameter, number of stigmatic rays on central capsule and number of capsules/plant. Hence, due emphasis should be given to the characters like capsule diameter, number of capsules/plant, and number of stigmatic rays on central capsule while selection of desired opium poppy genotypes. DSI, irrespective of experimental environments had highest direct and negative contribution to the straw yield and also contributed negatively and indirectly via capsule diameter, number of stigmatic rays on central capsule and number of capsules/plant. All these characters as expected contributed negatively to the straw yield production as DSI affected all these traits negatively. Plant 
height was the next higher direct negative contributor to straw yield production, which was followed by capsule length, leaf area and seed yield. The negative indirect effect of all these traits due to high DSI indicated the ability of downy mildew disease to cause straw yield losses. The relationships among some morphological traits have been reported earlier in opium poppy (Shukla and Khanna, 1987; Singh et al., 2003). However, the traits which are least affected by the natural environment, and which are working together are important and must be considered in selection based breeding programs specially designed for crop improvement. In the present study, characters like seed yield, straw yield, DSI for DM-resistance under natural (field) and artificial (glasshouse) epiphytotic conditions, stigmatic rays on central capsule and capsule diameter interacted very well together as it was evident by strong genotypic and phenotypic associations, and also have appreciable influence directly and indirectly towards straw yield due to positive and negative associations among them. Among these selected traits, capsule diameter was found to have the most strong correlation and direct or indirect effects on straw yield. Hence all the traits mentioned above, either in co-operation or simultaneously are the most reliable components for opium poppy breeding for selection of high seed-and strawyielding genotypes with downy mildew resistance.

In conclusion, our study suggests for the utilization of effectiveness of correlations and path analysis in developing reliable selection criteria in opium poppy. Utilization of distinct marker traits such as stigmatic rays and capsule diameter as selection criteria can greatly help in the development of high yielding and DM-resistant cultivars in opium poppy.

\section{ACKNOWLEDGEMENTS}

Financial assistance by Council of Scientific and Industrial Research (CSIR), Government of India, New Delhi as Senior Research Fellowship to the first author (MKD) is gratefully acknowledged. Authors also acknowledge Drs. A. Sattar and R.K. Lal for their help in DM screening and statistical analysis respectively and Dr. Sadhna Ålström for critically reading the manuscript.

\section{Literature Cited}

Dewey, D.R. and Lu, K.N. 1959. A correlation and path coefficient analysis of components of crested wheat grass seed production. Agron. J. 51:515-518.

Dubey, M.K. 2008. Developing DNA markers for straw alkaloid production and disease resistance in opium poppy (Papaver somniferum L). $\mathrm{PhD}$ thesis, University of Lucknow, Lucknow, India.

Dubey, M.K., Dhawan, O.P. and Khanuja, S.P.S. 2009. Downy mildew resistance in opium poppy: resistance sources, inheritance pattern, genetic variability and strategies for crop improvement. Euphytica 165:177-188.

Facchini, P.J. and Park, S.U. 2003. Developmental and inducible accumulation of gene transcripts involved in alkaloid biosynthesis in opium poppy. Phytochem. 64:177-186.

Falconer, D.S. 1989. Introduction to Quantitative Genetics. Third ed., Longman, London.

Hazel, L.N. 1943. The genetic basis of constructing selection indices. Genetics 28:276490.

Hussain, A. and Sharma, J.R. 1983.The Opium Poppy. Medicinal and Aromatic Plants Series-I. Central Institute of Medicinal and Aromatic Plants, Lucknow, India.

Jain, D.K., Jain, S.K., Bordia, P.C. and Joshi, A. 2005. Study of genetic variability and correlation in germplasm of opium poppy (Papaver somniferum L.). Res. Crops 6:112-115.

Lal, R.K., Sharma, J.R., Mishra, H.O. and Sharma, S. 1996. Divergence analysis and character association in opium poppy. J. Med. Arom. Plant Sci. 18:502-504.

Miller, P.A., Williams, V.C., Robinson, H.P. and Comstock, R.C. 1958. Estimates of genotypic and phenotypic environmental variances and covariances in upland cotton and their implications in selection. Agron. J. 5:126-136.

Mishra, S.N. and Drolsom, P.N. 1973. Association among certain morphological traits of 
diallel cross progenies in Bronus inermus LEYSS. J. Agric. Sci. Camb 81:69-76.

Scheiner, S.M., Michell, R.J. and Callahan, H.S. 2000. Using path analysis to measure natural selection. J. Evol. Biol. 13:423-433.

Sharma, J.R. and Gupta, M.M. 1994. Genetic and chemical analysis for alkaloids in Papaver. p.234-295. In: H.F. Linsken and J.F. Jackson (eds.), Modern Methods of Plant Analysis - Alkaloids. Springer Verlag, Berlin.

Shipley, B. 1997. Exploratory path analysis with application in ecology and evolution. Amer. Nat. 149:1113-1138.

Shukla, S. and Khanna, K.R. 1987. Genetic association in opium poppy. Indian J. Agric Sci. 57:147-151.

Singh, S.P. and Khanna, K.R. 1993. Path coefficient analysis for opium and seed yield in opium poppy (Papaver somniferum L.). Genetika 25:119-128.

Singh, S.P., Yadav, H.K., Shukla, S. and Chatterjee, A. 2003. Studies on different selection parameters in opium poppy (Papaver somniferum). J. Med. Arom. Plant Sci. 25:8-12.

Tetenyi, P. 1996. Opium poppy (Papaver somniferum): botany and horticulture. In: J. Janick (ed.), Horticultural Reviews. John Wiley \& Sons Inc. p.373-408.

Trivedi, M., Tiwari, R.K. and Dhawan, O.P. 2006. Genetic parameters and correlations of collar rot resistance with important biochemical and yield traits in opium poppy (Papaver somniferum L.). J. Appl. Genet. 47:29-38.

Williams, W.A., Jones, M.B. and Demment, M.W. 1990. A concise table for path analysis statistics. Agron. J. 82:1022-1024.

\section{Tables}

Table 1. Classification of 35 genotypes (germplasm/breeding lines and cultivars) selected for the study on the basis of their source of origin.

\begin{tabular}{lc}
\hline Source of origin & Germplasm lines/breeding lines/cultivars \\
\hline Germplasm lines & \\
Inbred lines developed from land races & Ib-38, IS-18, IS-22, I-264, I-266, I-267, I-293, \\
from Ghazipur, Uttar Pradesh, India & I-294, I-295, I-299, I-302, I-303, I-309, I-311, \\
& I-318, I-332. I-344, Y-ims \\
Inbred lines recovered from back cross & I-14, N-3 \\
progeny of the cross SPS-20 $\times$ SPS-49 & SPS-23, I-48 \\
Half sib selections from the gene pool & Thailand \\
Introductions & Pps-1, H-9 \\
$\begin{array}{l}\text { Spontaneous mutants } \\
\text { Selected breeding lines } \\
\text { Released cultivars }\end{array}$ & T-210, T-849, T-850, T-1018 \\
& Rakshit, Shweta Broad, Sanchita, Shubhra, \\
& Shyama, Jawahar-16 \\
\hline
\end{tabular}


Table 2. Mean values of different morphometric traits and disease severity index (DSI) for downy mildew in the selected 35 genotypes of opium poppy ${ }^{\mathrm{a}}$.

\begin{tabular}{|c|c|c|c|c|c|c|c|c|c|c|}
\hline \multirow{2}{*}{ Genotypes } & \multicolumn{10}{|c|}{ Morphometric traits ${ }^{b}$} \\
\hline & 1 & 2 & 3 & 4 & 5 & 6 & 7 & 8 & 9 & 10 \\
\hline \multicolumn{11}{|c|}{ Germplasm lines } \\
\hline $\mathrm{I}-14$ & 13.3 & 76.5 & 5.0 & 15.1 & 3.5 & 1.1 & 7.0 & 10.9 & 4.5 & 5.4 \\
\hline $\mathrm{I}-48$ & 12.2 & 96.4 & 5.5 & 15.6 & 3.5 & 1.2 & 43.1 & 50.8 & 4.2 & 5.4 \\
\hline $\mathrm{I}-264$ & 9.5 & 39.2 & 4.8 & 11.1 & 3.3 & 0.8 & 58.5 & 58.0 & 2.4 & 3.2 \\
\hline $\mathrm{I}-266$ & 9.3 & 60.4 & 3.9 & 8.8 & 3.3 & 0.4 & 57.1 & 77.1 & 1.3 & 1.9 \\
\hline $\mathrm{I}-267$ & 12.0 & 80.8 & 3.6 & 9.5 & 3.2 & 1.1 & 29.0 & 55.0 & 1.8 & 5.1 \\
\hline $\mathrm{I}-293$ & 11.6 & 85.7 & 5.0 & 12.8 & 3.0 & 1.1 & 57.4 & 76.6 & 2.2 & 3.7 \\
\hline I-294 & 11.6 & 82.1 & 5.4 & 14.7 & 3.0 & 1.1 & 63.8 & 68.5 & 2.4 & 4.0 \\
\hline $\mathrm{I}-295$ & 12.4 & 54.0 & 5.4 & 12.1 & 2.9 & 1.3 & 46.9 & 72.7 & 2.0 & 4.4 \\
\hline I-299 & 12.0 & 93.1 & 5.4 & 13.9 & 3.0 & 1.2 & 46.2 & 77.1 & 5.0 & 5.4 \\
\hline I-302 & 14.8 & 80.0 & 4.8 & 13.2 & 3.4 & 1.3 & 46.8 & 71.8 & 5.3 & 7.8 \\
\hline $\mathrm{I}-303$ & 12.8 & 85.7 & 5.2 & 15.2 & 3.3 & 1.3 & 46.4 & 74.4 & 5.2 & 6.0 \\
\hline I-309 & 11.7 & 73.3 & 4.5 & 14.2 & 2.9 & 1.1 & 50.5 & 59.6 & 3.1 & 4.4 \\
\hline I-311 & 10.2 & 34.6 & 4.0 & 9.0 & 3.1 & 1.1 & 39.3 & 64.2 & 1.3 & 3.4 \\
\hline $\mathrm{I}-318$ & 12.4 & 73.4 & 4.9 & 12.3 & 3.4 & 1.1 & 47.0 & 60.1 & 2.8 & 4.0 \\
\hline I-332 & 12.3 & 60.0 & 5.0 & 10.1 & 3.5 & 1.1 & 50.0 & 73.9 & 1.7 & 2.3 \\
\hline I-344 & 10.4 & 36.5 & 4.0 & 9.9 & 3.5 & 0.5 & 45.2 & 72.2 & 2.3 & 2.6 \\
\hline Ib-38 & 13.0 & 108.1 & 5.3 & 15.4 & 3.7 & 1.2 & 41.6 & 53.8 & 6.2 & 6.8 \\
\hline IS-18 & 13.8 & 112.1 & 5.8 & 16.4 & 4.1 & 1.3 & 37.2 & 55.0 & 5.7 & 7.7 \\
\hline IS-22 & 14.6 & 132.2 & 5.8 & 15.3 & 3.3 & 1.3 & 38.1 & 52.9 & 5.5 & 7.6 \\
\hline H-9 & 14.7 & 90.7 & 5.4 & 14.4 & 3.8 & 1.2 & 63.8 & 69.0 & 7.5 & 6.2 \\
\hline $\mathrm{N}-3$ & 13.2 & 96.0 & 5.7 & 15.9 & 3.6 & 1.2 & 23.0 & 30.6 & 4.3 & 5.3 \\
\hline Pps-1 & 13.1 & 76.2 & 5.0 & 15.1 & 3.7 & 1.1 & 7.0 & 10.9 & 4.3 & 5.6 \\
\hline SPS-23 & 14.7 & 137.6 & 6.1 & 16.8 & 4.3 & 1.1 & 41.6 & 48.1 & 7.8 & 7.5 \\
\hline Thailand & 15.0 & 165.2 & 6.4 & 16.3 & 3.7 & 1.0 & 67.5 & 80.5 & 6.2 & 7.7 \\
\hline Y-ims & 13.8 & 90.4 & 5.4 & 13.0 & 3.2 & 1.1 & 51.1 & 71.2 & 3.5 & 3.6 \\
\hline \multicolumn{11}{|c|}{ Selected breeding lines } \\
\hline $\mathrm{T}-210$ & 14.8 & 125.7 & 6.4 & 16.8 & 3.9 & 1.2 & 25.8 & 38.6 & 9.6 & 7.8 \\
\hline $\mathrm{T}-849$ & 15.4 & 130.4 & 6.5 & 17.0 & 4.0 & 1.1 & 28.5 & 32.3 & 10.0 & 6.9 \\
\hline T-850 & 14.1 & 130.5 & 6.8 & 17.4 & 3.9 & 1.3 & 25.2 & 47.8 & 10.2 & 9.1 \\
\hline $\mathrm{T}-1018$ & 14.7 & 129.4 & 6.5 & 17.2 & 4.0 & 1.1 & 24.9 & 33.2 & 8.7 & 7.0 \\
\hline \multicolumn{11}{|c|}{ Released varieties } \\
\hline Rakshit & 14.6 & 103.2 & 6.2 & 16.7 & 4.3 & 1.3 & 21.0 & 22.1 & 10.1 & 9.1 \\
\hline Shweta Broad & 14.5 & 145.3 & 6.7 & 16.8 & 4.4 & 1.2 & 48.0 & 60.1 & 9.1 & 7.1 \\
\hline Sanchita & 13.6 & 120.5 & 6.9 & 16.8 & 4.5 & 1.2 & 61.4 & 50.0 & 9.1 & 6.8 \\
\hline Shubhra & 13.9 & 116.1 & 6.8 & 16.1 & 4.4 & 1.1 & 66.4 & 71.1 & 8.7 & 6.6 \\
\hline Shyama & 14.4 & 127.0 & 6.4 & 15.9 & 4.1 & 1.2 & 47.9 & 59.7 & 7.9 & 6.5 \\
\hline Jawahar-16 & 15.4 & 138.3 & 5.9 & 17.1 & 3.9 & 1.1 & 79.5 & 88.6 & 6.2 & 4.6 \\
\hline
\end{tabular}

${ }^{a}$ Mean values of the given parameters were calculated from the data recorded over three consecutive cropping seasons (2004-05 to 2006-07).

b (1) Number of stigmatic rays on central capsule; (2) Leaf area $\left(\mathrm{cm}^{2}\right)$ of third leaf from top; (3) Capsule length (cm) of central capsule; (4) Capsule diameter (cm) of central capsule; (5) Number of capsules/plant; (6) Plant height (m); (7) DSI (\%) in glasshouse; (8) DSI (\%) in field; (9) Seed yield (g)/capsule (central);

(10) Straw yield/capsule (central). 
Table 3. Categorization of the selected 35 germplasm accessions on the basis of disease severity index for downy mildew resistance in glasshouse and field conditions.

\begin{tabular}{lcc}
\hline Category & Glasshouse condition & Field condition \\
\hline HR (highly resistant) & I-14, Pps-1 & I-14, Pps-1 \\
R (resistant) & N-3, Rakshit, T-210, T-850, & N-3, Rakshit, T-210, T-850, \\
T (tolerant) & T-849, T-1018 & T-849, T-1018 \\
& Ib-38, IS-18, IS-22, I-267, & Ib-38, IS-18, IS-22, I-267 \\
& I-295, I-299, I-302, I-303, & \\
S (susceptible) & I-311, I-318, I-332, I-344 & \\
& H-9, SPS-23, Shweta Broad, & H-9, SPS-23, Shweta Broad, \\
& Sanchita, Shubhra, Shyama, & Sanchita, Shyama, I-48, I-264, \\
& Thailand, I-48, I-264, I-266, & I-266, I-293, I-294, I-295, I-299, \\
& I-293, I-294, I-309, & I-302, I-303, I-309, I-311, I-318, \\
& Y-ims & I-332, I-344, Y-ims \\
HS (highly susceptible) & Jawahar-16 & Jawahar-16, Shubhra, Thailand \\
\hline
\end{tabular}




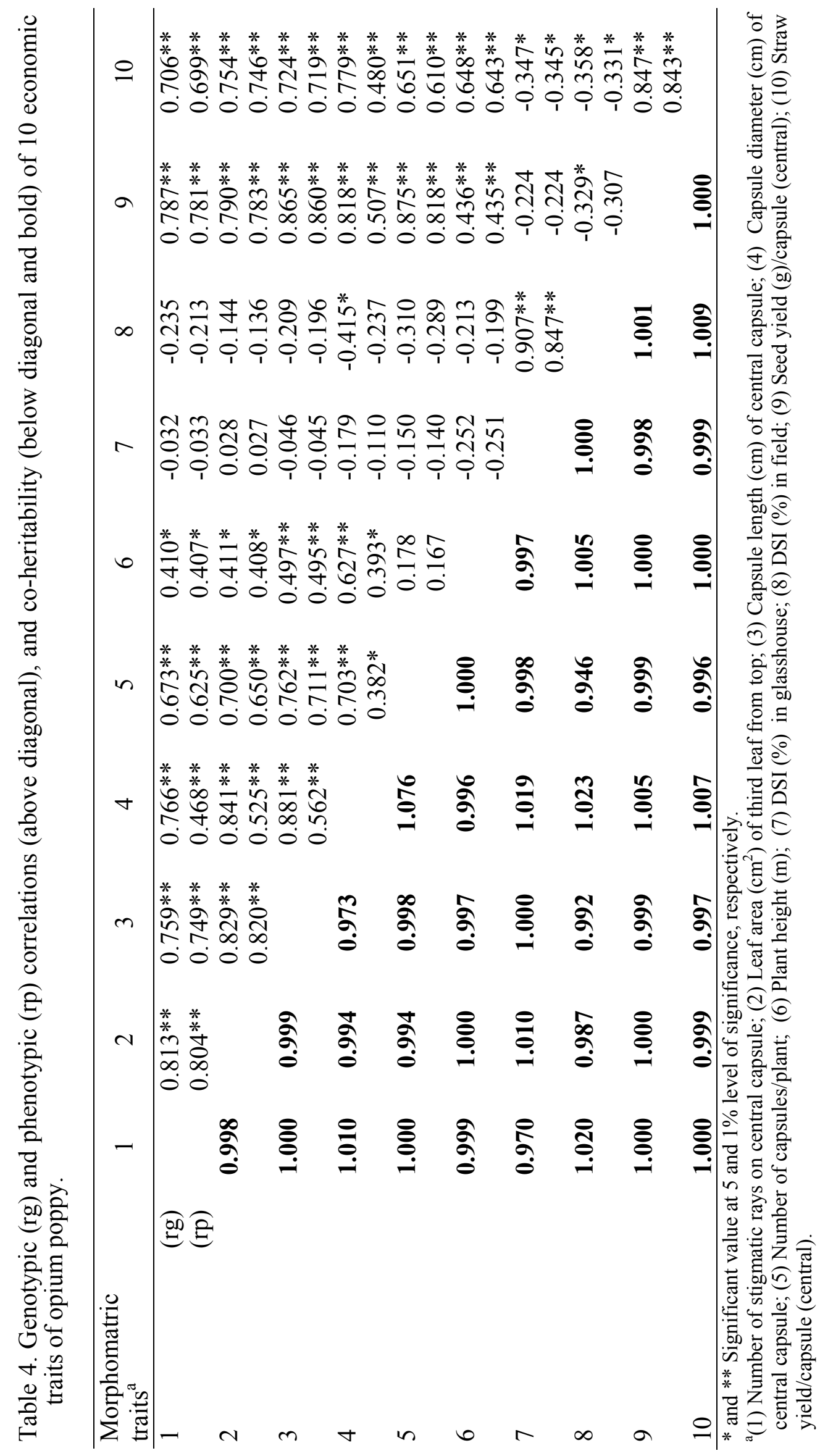




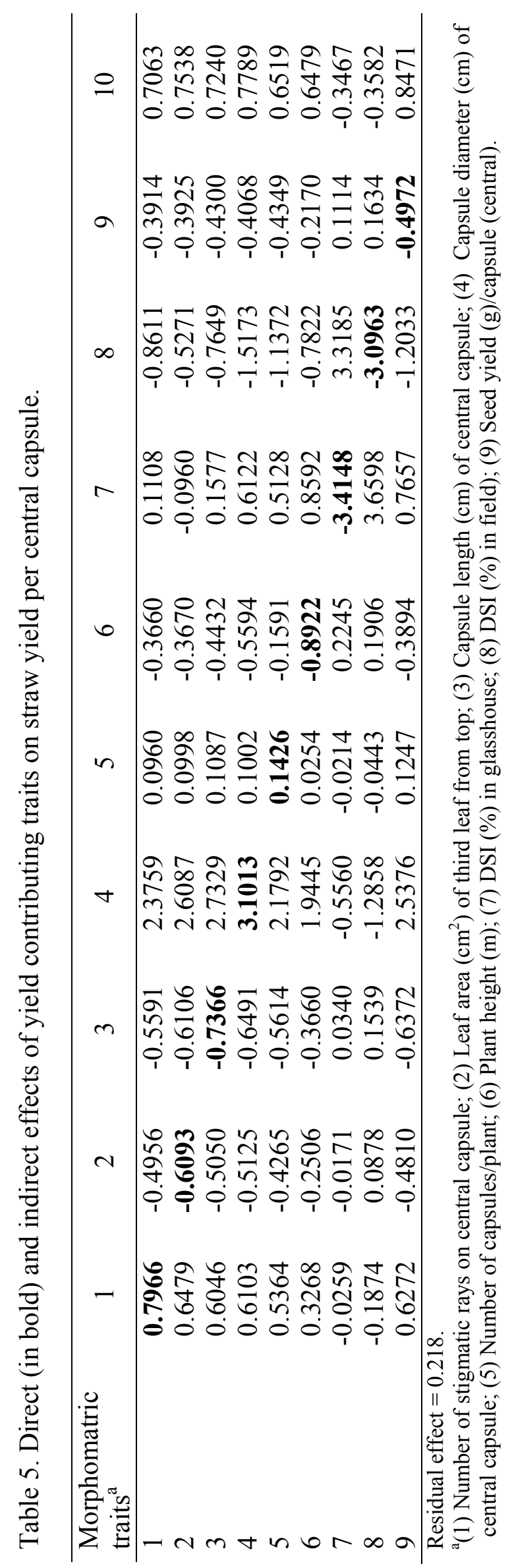


